\title{
Editorial
}

\section{Solar Energy and PV Systems}

\author{
Ismail H. Altas ${ }^{1}$ and Adel M. Sharaf ${ }^{2}$ \\ ${ }^{1}$ Karadeniz Technical University, 61080 Trabzon, Turkey \\ ${ }^{2}$ Sharaf Energy Systems Inc., Fredericton, NB, Canada E3C 2P2 \\ Correspondence should be addressed to Ismail H. Altas; ihaltas@altas.org
}

Received 20 November 2014; Accepted 20 November 2014; Published 22 December 2014

Copyright (C) 2014 I. H. Altas and A. M. Sharaf. This is an open access article distributed under the Creative Commons Attribution License, which permits unrestricted use, distribution, and reproduction in any medium, provided the original work is properly cited.

The utilization of solar photovoltaic (PV) systems has gained a tremendous momentum due to decreasing costs of PV arrays and interface systems by as much as $50 \%$ during the last five years. The advancements on electric utility grid interface systems and utilization of PV arrays in standalone local power generation and smart buildings with storage battery and back-up hybrid systems are increasing the PV system utilization as the emerging form of renewable/alternative energy source. In many countries, the government has instituted special incentives and tax credits as well as feed-in tariff and energy purchase back legislation programs in order to promote and encourage manufacturers and consumers and boost new investments in solar PV energy use in different sectors.

As the solar PV systems emerge as viable and economic source of green energy with increasing installation sites every year, attempts are made to find economic and technological solutions to the problems arising from various aspects of the PV utilization schemes. The state of the art research is continuing in all areas from material sciences to manufacturing and interfacing in order to ensure efficient utilization and commercial viability in terms of cost, security, and durability of PV and hybrid PV-wind-storage systems. Specific areas focus on PV array topologies, dynamic sun tracking, maximum power point control, storage devices, and efficient decoupled interface with smart grid and smart building to ensure dynamic matching of energy to load requirements with minimal impact on the host utility grid. Besides, energy management studies in smart grids and distributed generation have become other additional areas of demand side management and energy efficient hybrid utilityrenewable energy.

We invited investigators to contribute original research articles as well as review articles that will stimulate the continuing efforts and promote new research directions to address the undergoing challenges and technological requirements in PV systems utilization in order to ensure commercial viability and improve usability, security, reliability, and integration of sustainability of converting sun power to electricity.

Hybrid PV-wind-fuel cell-microgas turbines with storage Li-ion batteries and super capacitors are promising to modify the way smart grid manages efficient electrical energy and ensure demand-side management and peak shifting as well as shaving of peak demand during summer months due to massive air-conditioning loads.

The inherent problems of PV interfacing include the effects of solar insulation and temperature changes affecting the PV array power/energy as well as interface power quality and required dc-ac isolation and grid supply security and reliability.

The effects of mismatching conditions and partial shading/clouding problems require novel control and power tracking algorithms, new architecture using multi converters, and sitting/location dynamic exchanges of PV arrays using series-parallel (SP) topologies.

The special edition is a collection of accepted papers focused on photovoltaic systems emerging technology and current applications including interfacing, energy efficient utilization, emerging technologies, fabrication, and new control strategies for maximum power point tracking under 
contingencies, mismatching, and cloudy/partial shading conditions with PV farm/park utilization and field studies. Technologies using solar energy in heating and cooling systems, advancements in manufacturing processes, developments in power electronic devices for utility interfacing issues, shading effects, maximum power point tracking algorithms, and efficient energy management for higher efficiency in PV systems are some other topics presented in this special issue.

Ismail H. Altas Adel M. Sharaf 

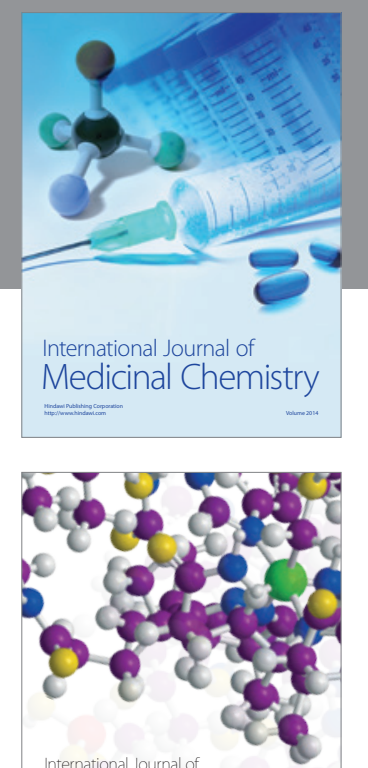

\section{Carbohydrate} Chemistry

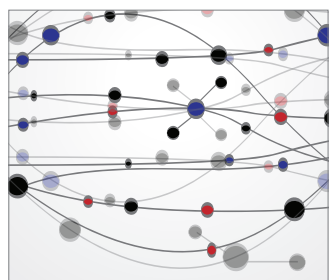

The Scientific World Journal
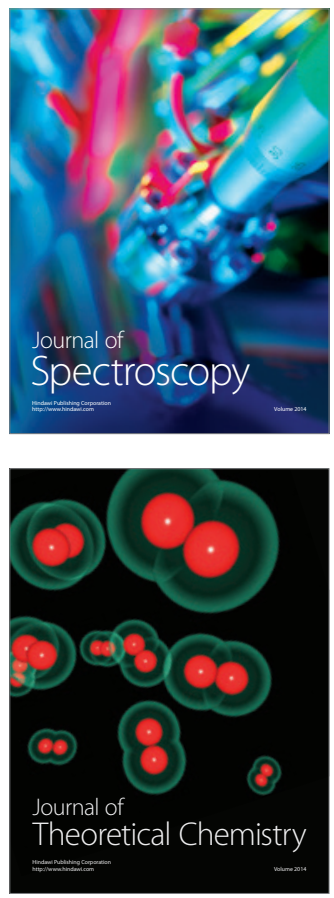
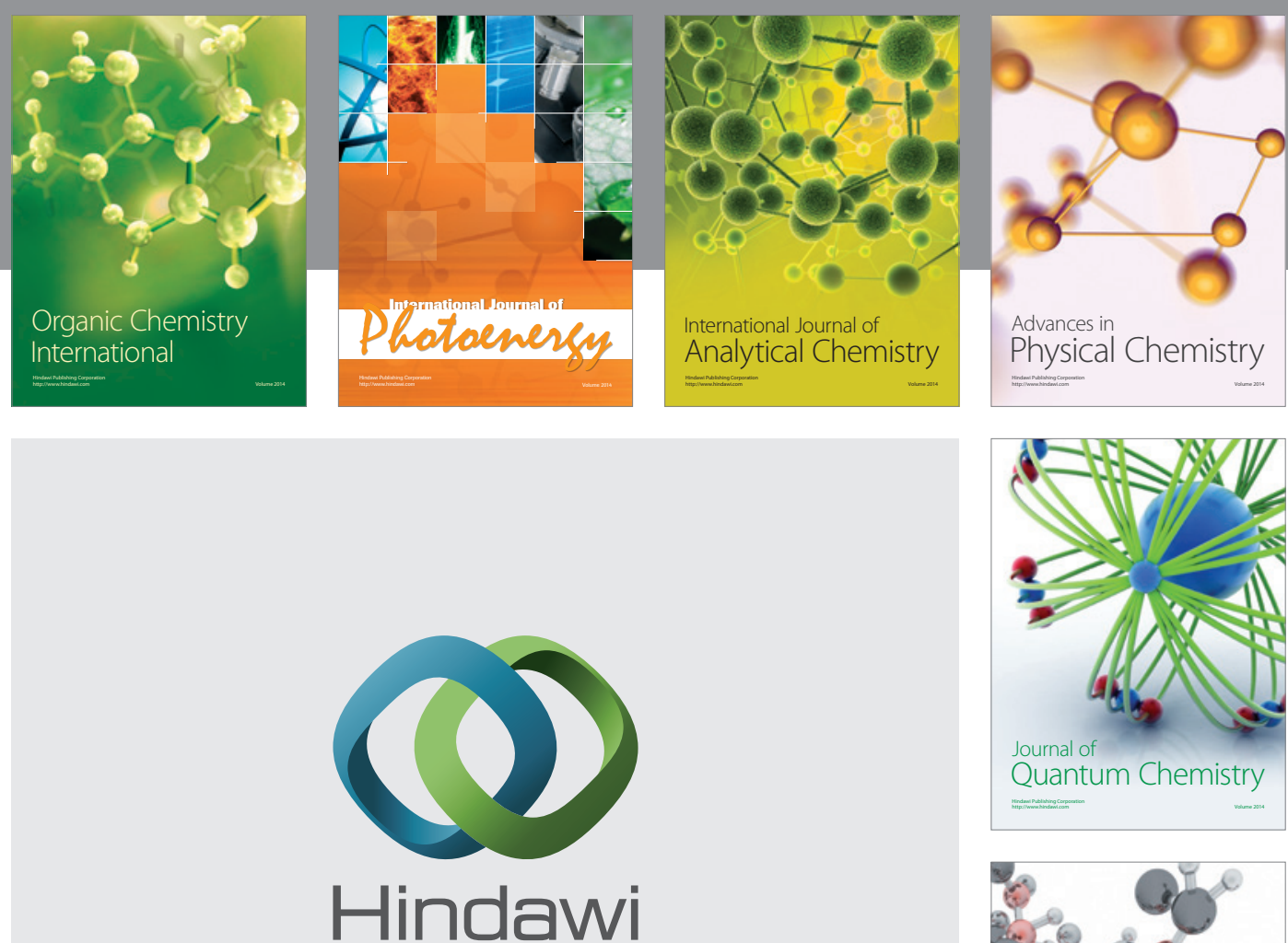

Submit your manuscripts at

http://www.hindawi.com

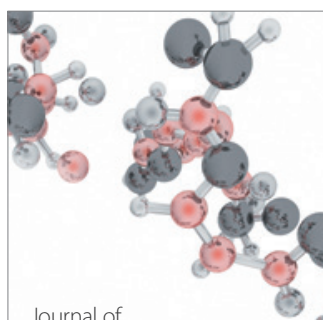

Analytical Methods

in Chemistry

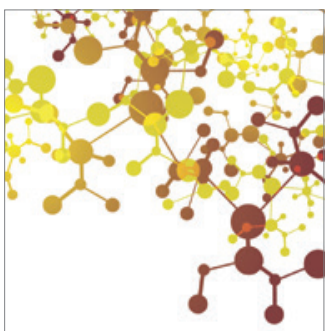

Journal of

Applied Chemistry

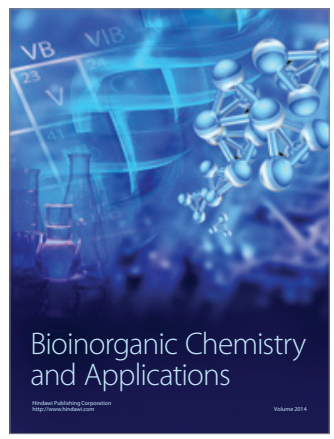

Inorganic Chemistry
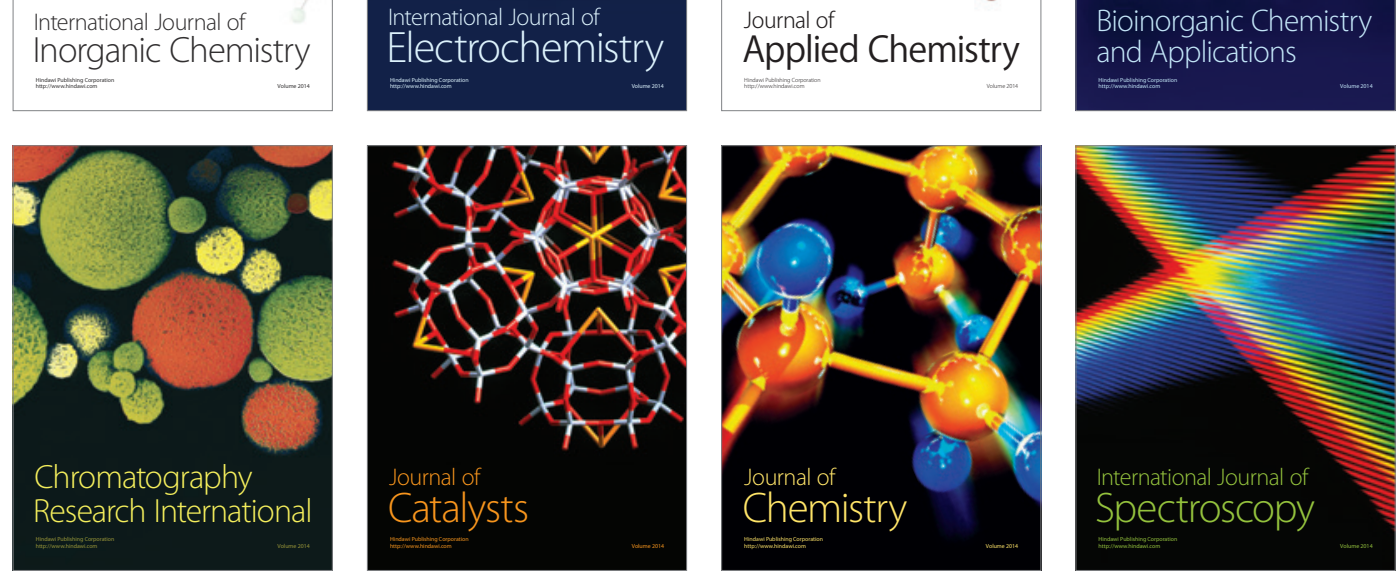